\title{
Corrigendum: Middle Meningeal Artery Embolization for Chronic Subdural Hematoma
}

\author{
Joshua S. Catapano, Candice L. Nguyen, Andre A. Wakim, Felipe C. Albuquerque and \\ Andrew F. Ducruet* \\ Department of Neurosurgery, Barrow Neurological Institute, Phoenix, AZ, United States
}

Keywords: chronic subdural hematoma, cSDH, middle meningeal artery embolization, endovascular cSDH treatment, MMA embolization

\section{A Corrigendum on}

Middle Meningeal Artery Embolization for Chronic Subdural Hematoma

by Catapano, J. S., Nguyen, C. L., Wakim, A. A., Albuquerque, F. C., and Ducruet, A. F. (2020). Front. Neurol. 11:557233. doi: 10.3389/fneur.2020.557233

\section{OPEN ACCESS}

Approved by:

Frontiers Editorial Office,

Frontiers Media SA, Switzerland

*Correspondence:

Andrew F. Ducruet

Neuropub@barrowneuro.org

Specialty section:

This article was submitted to Endovascular and Interventional

Neurology,

a section of the journal

Frontiers in Neurology

Received: 10 February 2021 Accepted: 23 February 2021

Published: 22 March 2021

Citation:

Catapano JS, Nguyen CL, Wakim AA, Albuquerque $F C$ and Ducruet $A F$

(2021) Corrigendum: Middle

Meningeal Artery Embolization for

Chronic Subdural Hematoma.

Front. Neurol. 12:666701.

doi: 10.3389/fneur.2021.666701
In the original article, there were errors in the text.

A correction has been made to Discussion, Future Direction. The corrected paragraph is shown below:

Several randomized control trials investigating the efficacy, safety, and utility of MMA embolization for cSDHs are underway $(15,16,58-63)$. Additionally, various embolisates for MMA embolization are currently being studied. The SQUID Trial for the Embolization of the Middle Meningeal Artery for Treatment of Chronic Subdural Hematoma (STEM) is a randomized control trial that is investigating the safety and efficacy of SQUID for the management of cSDHS (61). Another embolisate currently being analyzed is Onyx, which is being evaluated in the Embolization of the Middle Meningeal Artery with ONYX Liquid Embolic System for Subacute and Chronic Subdural Hematoma (EMBOLISE) (62). Both of these trials are comparing medical management alone to MMA embolization, and surgical treatment with embolization to surgical treatment alone. Because the literature on MMA embolization of cSDHs includes a large number of patients who also received surgical intervention, randomized control trials will need to be conducted in a manner to also elucidate the appropriate patient selection for either MMA embolization alone or in combination with surgical intervention.

The authors apologize for this error and state that this does not change the scientific conclusions of the article in any way. The original article has been updated.

Copyright (c) 2021 Catapano, Nguyen, Wakim, Albuquerque and Ducruet. This is an open-access article distributed under the terms of the Creative Commons Attribution License (CC BY). The use, distribution or reproduction in other forums is permitted, provided the original author(s) and the copyright owner(s) are credited and that the original publication in this journal is cited, in accordance with accepted academic practice. No use, distribution or reproduction is permitted which does not comply with these terms. 